University of Nebraska - Lincoln

DigitalCommons@University of Nebraska - Lincoln

Faculty Publications, Department of Psychology

Psychology, Department of

2012

Differential effects of acute amphetamine and phencyclidine treatment and withdrawal from repeated amphetamine or phencyclidine treatment on social interaction and social memory in rats

Ming Li

University of Nebraska-Lincoln, mli2@unl.edu

Wei He

University of Nebraska-Lincoln

Rebecca Munro

University of Nebraska-Lincoln

Follow this and additional works at: http://digitalcommons.unl.edu/psychfacpub

Part of the Behavior and Behavior Mechanisms Commons, Chemical Actions and Uses Commons, Pharmacy and Pharmaceutical Sciences Commons, Psychology Commons, and the Substance Abuse and Addiction Commons

Li, Ming; He, Wei; and Munro, Rebecca, "Differential effects of acute amphetamine and phencyclidine treatment and withdrawal from repeated amphetamine or phencyclidine treatment on social interaction and social memory in rats" (2012). Faculty Publications, Department of Psychology. 707.

http:// digitalcommons.unl.edu/psychfacpub/707

This Article is brought to you for free and open access by the Psychology, Department of at DigitalCommons@University of Nebraska - Lincoln. It has been accepted for inclusion in Faculty Publications, Department of Psychology by an authorized administrator of DigitalCommons@University of Nebraska - Lincoln. 


\title{
Differential effects of acute amphetamine and phencyclidine treatment and withdrawal from repeated amphetamine or phencyclidine treatment on social interaction and social memory in rats
}

\author{
Ming Li, Wei He, and Rebecca Munro \\ Department of Psychology, University of Nebraska-Lincoln, Lincoln, NE, USA \\ Corresponding author - Professor Ming Li, Department of Psychology, University of Nebraska-Lincoln, 238 Burnett Hall, Lincoln, NE \\ 68588-0308, USA; email mli2@unl.edu
}

\begin{abstract}
Although animal models based on amphetamine (AMPH) or phencyclidine (PCP) treatment have been used extensively to study the neurobiological and behavioral characteristics of schizophrenia, there are conflicting reports regarding their validity in modeling the negative symptoms and cognitive deficits of schizophrenia. The present study examined how acute AMPH or PCP treatment (Experiment 1) and withdrawal from repeated AMPH treatment (Experiment 2) or PCP treatment (Experiment 3) affects social behavior and social recognition memory in male Sprague-Dawley rats. Each subject was tested on two consecutive days. On the first day, the rats were tested four times (5 min/each) at 10-min intervals with the same partner rat (termed "AAAA" day). One day later, the rats were tested with the previous partner in the first three sessions and with a new partner rat in the final session (termed "AAAB" day). The results show that acute AMPH treatment $(1.5 \mathrm{mg} / \mathrm{kg}, \mathrm{sc})$ significantly reduced the time spent on social interaction, but did not affect social recognition on the first day. Acute AMPH only disrupted social recognition on the second day of drug testing. In contrast, acute PCP treatment $(2.0 \mathrm{mg} / \mathrm{kg}, \mathrm{sc})$ had no effect on time spent on social interaction, but did significantly disrupt social recognition on both days. Withdrawal from repeated AMPH (3.0 mg/kg/day for 7 days, ip) or PCP $(5.0 \mathrm{mg} / \mathrm{kg} / \mathrm{twice}$ daily for 7 days, ip) treatment did not affect social interaction or social recognition, indicating a lack of long-term detrimental effect of repeated AMPH or PCP treatment. These results suggest that acute AMPH treatment at a low dose (1.5 $\mathrm{mg} / \mathrm{kg}$ ) may be useful in modeling social withdrawal symptoms of schizophrenia, whereas acute PCP treatment at a similar dose range $(2.0 \mathrm{mg} / \mathrm{kg})$ may be useful in modeling the social cognitive deficit of schizophrenia.
\end{abstract}

Keywords: amphetamine, phencyclidine, rat, schizophrenia, social interaction, social recognition

Schizophrenia is a debilitating and chronic mental disorder that affects approximately $1 \%$ of the world's population. Patients with schizophrenia often live alone, display social withdrawal, and experience difficulties recognizing facial expressions (Krishnan, Keefe, \& Kraus, 2009; Reske et al., 2009). This type of social functioning deficit (e.g., social withdrawal and social cognitive deficit) is of great concern to patients and their families and friends, as it directly influences how effectively patients with schizophrenia communicate and develop networks of support with those around them (Green et al., 2004).
Rat social behavior under the influence of amphetamine (AMPH) or phencyclidine (PCP) has been used as a simplified model for social deficits in schizophrenia (Ellenbroek \& Cools, 1990; Kilts, 2001; Sams-Dodd, 1999; Tanaka et al., 2003). Despite considerable literature in this line of research, there are several important issues that have not been adequately addressed. The first issue concerns the ability of AMPH to induce social withdrawal in rodents. While most PCP studies seem to suggest that acute and subchronic treatment of PCP can reduce social interaction dose-dependently (Lee, Brady, Shapiro, Dorsa, \& Koenig, 2005; 
Qiao et al., 2001; Sams-Dodd, 1995, 1998a; Tanaka et al., 2003), this is not the case with AMPH (Young, Gobrogge, \&Wang, 2011). Some studies report that acute AMPH reduces social interaction (Gambill \& Kornetsky, 1976; Schiorring \& Hecht, 1979; Steinpreis, Sokolowski, Papanikolaou, \& Salamone, 1994), while other studies fail to show such an effect (Qiao et al., 2001; Sams-Dodd, 1995, 1998b), and still others report an enhancing effect on rat social behavior (Guy \& Gardner, 1985).

The second issue concerns the lack of systematic research on the AMPH and PCP models for social functioning deficits and their comparative validity. To our knowledge, there are only two studies that have examined the long-term effects of (meth)amphetamine and PCP sensitization on rodent social behavior. Both reported that only PCP sensitization disrupted social interaction in mice (Qiao et al., 2001) and rats (Lee et al., 2005), and that this effect could persist for at least 28 days after the drug withdrawal (Qiao et al., 2001). However, most studies have focused on the acute effects of AMPH and PCP on social interaction (SamsDodd, 1995; Steinpreis et al., 1994), making it difficult to tease apart the enduring and intrinsic effect on social behavior from the transient confusion effect (Qiao et al., 2001).With regards to the relative validity, some suggest that the PCP model is better, because it induces thought disorders and negative symptoms, such as social withdrawal in rodents (Qiao et al., 2001; Sams-Dodd, 1998a, 1998b). For example, Qiao et al. (2001) found that withdrawal from repeated PCP treatment, but not from (meth)amphetamine, reduced social interaction in mice. However, this finding is at odds with some clinical (Srisurapanont et al., 2003) and preclinical observations (Ellenbroek \& Cools, 2000). There are still other researchers suggesting that the AMPH model is better because only the AMPH sensitization withdrawal model in animals is capable of reproducing information-processing deficits that are impaired in schizophrenia, as measured in prepulse inhibition (PPI), latent inhibition and attentional set shifting tasks (Fletcher, Tenn, Rizos, Lovic, \& Kapur, 2005; Tenn, Kapur, \& Fletcher, 2005). Studies that directly compare the acute and subchronic effects of AMPH and PCP in social behavior models encompassing a social cognition component may help address this issue.

In the present study, we attempted to address these issues using a repeated social interaction testing paradigm. We examined and compared the ability of acute and repeated AMPH and PCP treatment in reproducing social withdrawal and social recognition (a type of working memory) deficit, one of seven primary cognitive domains that are affected in schizophrenia (Floresco, Geyer, Gold, \& Grace, 2005; Green et al., 2004). In this task, a subject rat was given multiple encounters with a partner rat (weight-matched) in a new testing cage. The social memory of rats is evidenced by the findings that a normal rat will decrease its time investigating the same testing partner after a waiting period (approximately $10 \mathrm{~min}$ ) and will increase its time on investigation if a novel partner is introduced (Akers et al., 2006; Holloway \& Thor, 1988; Prediger, Batista, Miyoshi, \& Takahashi, 2004). Therefore, this paradigm allowed us to examine not only the effects of AMPH and PCP on social interaction, but also their impacts on social cognition (social recognition) in a natural behavior context (Akers et al., 2006; Holloway \& Thor, 1988; Prediger et al., 2004).

\section{Methods}

\section{Animals}

Male Sprague-Dawley rats (226-250 g on arrival; Charles River, Portage, MI, USA) were housed two per cage, in $48.3 \mathrm{~cm} \times 26.7 \mathrm{~cm} \times 20.3 \mathrm{~cm}$ transparent polycarbonate cages with food and tap water available ad lib. The subjects were maintained on a day-night cycle of $12 \mathrm{hr}: 12 \mathrm{hr}$ (light on between 6:30 a.m. and 6:30 p.m.). The room temperature was maintained at $22 \pm$ $1^{\circ} \mathrm{C}$ and the humidity was controlled at $45-60 \%$. The subjects were housed at the animal facility for at least 7 days before they were used in the behavioral testing. This animal use protocol was approved by the local Institutional Animal Care and Use Committee.

\section{Drugs}

Dextroamphetamine sulfate was purchased from Sigma-RBI and phencyclidine hydrochloride was gift from the NIDA Chemical Synthesis and Drug Supply Program. They were dissolved in $0.9 \%$ saline. All injections were administered at a volume of $1 \mathrm{ml} / \mathrm{kg}$.

\section{Experiment 1: Effect of acute AMPH and PCP treat- ment on social interaction and social recognition}

Prior to testing, 24 experimental rats were randomly assigned to one of three groups: those treated with saline (SAL, $n=8)$, AMPH $(n=8)$, or PCP $(n=8)$. They were termed "subjects." Another 12 rats were simply used as partners for the social behavior tests (termed "partners"). All rats were first handled for 2 days. On each handling day, the subject rats in the SAL, AMPH, 
Figure 1. A schematic depiction of the experimental procedure in Experiment 1.

\begin{tabular}{|c|c|c|c|c|c|c|c|c|c|}
\hline & & & $\begin{array}{l}\text { Trial } 1 \\
5 \mathrm{~min}\end{array}$ & & $\begin{array}{c}\text { Trial } 2 \\
5 \mathrm{~min}\end{array}$ & & $\begin{array}{l}\text { Trial } 3 \\
5 \mathrm{~min}\end{array}$ & & $\begin{array}{l}\text { Trial } 4 \\
5 \mathrm{~min}\end{array}$ \\
\hline $\begin{array}{l}\text { Day } 1 \\
\text { AAAAA }\end{array}$ & \multirow{2}{*}{ Injection } & \multirow{2}{*}{$\begin{array}{c}10 \\
\min \end{array}$} & Partner A & \multirow{2}{*}{$\begin{array}{c}10 \\
\mathrm{~min}\end{array}$} & Partner A & \multirow{2}{*}{$\begin{array}{c}10 \\
\min \end{array}$} & Partner A & \multirow{2}{*}{$\begin{array}{c}10 \\
\min \end{array}$} & Partner A \\
\hline $\begin{array}{l}\text { Day } 2 \\
\text { AAAB }\end{array}$ & & & Partner A & & Partner A & & Partner A & & Partner B \\
\hline
\end{tabular}

and PCP groups were handled for approximately 2 min each, given subcutaneous injections of saline, and placed into large transparent observation cages $(51 \mathrm{~cm}$ $\times 38.1 \mathrm{~cm} \times 19 \mathrm{~cm}$ ) with wood shavings for bedding for $5 \mathrm{~min}$. The rats in the partner group were handled on the same 2 days but did not receive any injections. They were housed in separate cages from the experimental rats.

Following handling, each subject rat received two consecutive days of testing. On each test day, the subject first received a single subcutaneous injections of saline, AMPH $1.5 \mathrm{mg} / \mathrm{kg}$, or PCP $2.0 \mathrm{mg} / \mathrm{kg}$ and was immediately placed into an observation cage. Ten minutes later, the first partner was introduced to the subject, and social interaction was videotaped for $5 \mathrm{~min}$, after which the partner was removed and returned to a separate holding cage. This procedure was repeated three additional times at 10-min intervals, thereby giving every subject four 5-min test sessions per day. To distinguish between the partner rats and the subject rats, the former were tagged by drawing stripes on their back with a black marker. On Day 1, each subject was tested with the same partner in all four sessions. This day was termed the "AAAA" day, denoting that the four 5-min tests used the same "A" partner. On Day 2, 10 min after saline, AMPH $1.5 \mathrm{mg} / \mathrm{kg}$, or PCP $2.0 \mathrm{mg} / \mathrm{kg}$ injection, each subject was again tested with the previous partner ("A") in the first three sessions and with a new partner ("B") in the final session. This day was termed the "AAAB" day (see Figure 1 for the general experimental procedure).

The amount of time (in seconds, $300 \mathrm{~s}$ max) that a subject rat engaged in social behaviors, including sniffing (whole body and anogenital area), climbing over and crawling underneath the partner, grooming, boxing, and closely following its partner, was later scored by two trained raters using JWatcher behavioral coding software (http://www.jwatcher.ucla.edu/). Please note that any social contact initiated by the partner was not counted to ensure an accurate recording of only drug-induced disruption of social behavior. The results from each rater were compared and averaged if the differences were less than $20 \mathrm{~s}$. Otherwise, the disputed test sessions were recoded by the two raters and by an additional trained rater. The subsequent results were compared and the two closest data points were averaged. Because many of the individual social behaviors often occurred simultaneously and could not be easily distinguished, we totaled the time spent on social interaction and used it for data analysis. Social memory was indexed by the across-session, progressive decline in the time spent on social interaction on the AAAA day, and the initial decline in the first three sessions and recovery of the interaction time in the last session on the AAAB day. Thus, to examine the effects of acute AMPH and PCP on social recognition memory, we used the following formulas to calculate the social memory indices for each subject:

$$
\begin{aligned}
& \text { Social memory on AAAA day } \\
& \quad=[(\text { session } 4-\text { session } 1) \div \text { session } 1] \times 100 \% \\
& \text { Social memory on AAAB day } \\
& \quad=[(\text { session } 3-\text { session } 1) \div \text { session } 1] \times 100 \%
\end{aligned}
$$

The above formulas calculated the percentage change in social interaction time from the first session to the fourth or third session. The AMPH and PCP doses were chosen because they are commonly used in the literature (Arnt, 1995; Gleason \& Shannon, 1997; Mintz, Russig, Lacroix, \& Feldon, 2005; Natesan, Reckless, Nobrega, Fletcher, \& Kapur, 2006; Sams-Dodd, 1998b; Sills, Greenshaw, Baker, \& Fletcher, 2000; Steinpreis et al., 1994; Sun, Hu, \& Li, 2009). All social behavior tests were run during the light cycle at approximately the same time on both days.

\section{Experiment 2: Effect of withdrawal from repeated AMPH treatment on social interaction and social recognition}

Twenty-four rats were pseudo-randomly assigned to one of three groups ( $n=8$ /group; SAL, AMPH, or control) so that the rats housed in the same cages received the same drug treatment. After 1 week of habituation and 2 days of handling ( $1 \mathrm{~min} / \mathrm{rat} /$ day $)$, the rats in the AMPH and SAL groups received intraperitoneal injections of $3.0 \mathrm{mg} / \mathrm{kg}$ AMPH or saline $(0.9 \%, 1 \mathrm{ml} / \mathrm{kg})$, respectively, once daily for seven consecutive days. As in Experiment 1, the rats in the partner group were handled but did not receive any injections. This AMPH treatment regimen was chosen based on previous 
reports that it produces robust locomotor sensitization and enhances behavioral responses to reward (Avena \& Hoebel, 2003; Wyvell \& Berridge, 2001). The social behavior tests started 1 week after the last drug injection. The basic procedure was identical to that of Experiment 1 . The rats were first tested with the same partner rat in all four sessions on the AAAA day. One day later, the subject rat was tested with the previous partner in the first three sessions and with a new partner in the final session on the AAAB day.

\section{Experiment 3: Effect of withdrawal from repeated PCP treatment on social interaction and social recognition}

In Experiment 3, 24 rats were pseudo-randomly assigned to one of three groups ( $n=8$ /group; SAL, PCP, or control). The rats in the PCP and SAL groups received twice-daily injections of $5.0 \mathrm{mg} / \mathrm{kg} \mathrm{PCP}$ or $0.9 \%$ saline $(1 \mathrm{ml} / \mathrm{kg})$ at approximately 8:00 a.m. and 6:00 p.m. for seven consecutive days prior to social behavior testing. This PCP treatment regimen is shown to induce a decrease in prefrontal dopaminergic utilization, augmented motor activity, and various cognitive deficits (Dunn \& Killcross, 2006; Jentsch \& Taylor, 2001; Jentsch, Tran, Le, Youngren, \& Roth, 1997; Rodefer, Murphy, \& Baxter, 2005). Similar to Experiment 2, social behavior tests started 1 week after the last drug injection, and each rat was tested on two consecutive days (i.e., AAAA and AAAB day).To monitor the progress of behavioral sensitization with repeated PCP treatment, both PCP and saline-treated rats were tested in a motor activity monitoring system over the treatment period: (1) the day before the first drug injection; (2) immediately after the first injection; (3) immediately after the seventh injection and (4) immediately after the 14th injection for $60 \mathrm{~min}$. The testing boxes were $48.3 \mathrm{~cm} \times 26.7 \mathrm{~cm} \times 20.3 \mathrm{~cm}$ transparent polycarbonate cages, each equipped with a row of six photocell beams ( $7.8 \mathrm{~cm}$ between two adjacent photo beams) placed $3.2 \mathrm{~cm}$ above the floor of the cage. A computer detected the disruption of the photocell beams and recorded the number of beam breaks.

\section{Statistical analysis}

To identify the treatment effects, the total time spent on social interaction on each test day (the sum of four sessions) and measurements of social memory were analyzed using a one-way analysis of variance (ANOVA) with the treatment as the between-subjects factor, followed by a post hoc least significant difference (LSD) test. To identify changes across sessions, the data were analyzed using repeated-measures ANOVA with the treatment as the between-subjects factor ("Treatment": AMPH, PCP, or SAL) and the test sessions ("Session": $\mathrm{AAAA}$ or $\mathrm{AAAB}$ ) as the within-subjects factor, followed by a post hoc LSD test. Any PCP-induced change in motor activity was analyzed using repeated-measures ANOVA. A conventional two-tailed level of significance at the $5 \%$ level was required for all tests.

\section{Results}

\section{Experiment 1: Effect of acute AMPH and PCP treatment on social interaction and social recognition}

\section{Acute AMPH treatment, but not PCP reduced social interaction}

Figure 2 shows the total time spent on social interaction on each test day (a sum of the four sessions from the AAAA and AAAB test days) for each treatment group. It appears that acute AMPH $(1.5 \mathrm{mg} / \mathrm{kg}$, sc) treatment reduced social interaction, particularly on the AAAB day. In contrast, acute PCP $(2.0 \mathrm{mg} / \mathrm{kg}$, sc) treatment had little effect on this measure. Oneway ANOVA confirmed this observation. On the AAAA day, there was a significant effect of "Treatment," $F(2$, $23)=14.629, p<.001$. Post hoc tests indicate that the AMPH group was significantly different from the SAL group, $p<.001$, whereas the PCP group was not, $p=$ .618. On the AAAB day, the treatment effect was not statistically significant, $F(2,23)=2.495, p=.107$, also the AMPH group was only marginally different from the SAL group, $p=.052$, suggesting that the last session with a novel partner (i.e., the "B" session in the "AAAB") on that day may have attenuated the disruptive effect of AMPH to some extent.

To gain a more detailed understanding of the acute effect of AMPH and PCP treatment on social behavior, we depict social interaction time across the four sessions on the two test days in Figure 3. Once again, the disruptive effect of AMPH was apparent (Figure $3 \mathrm{~A})$. For the AAAA day, repeated-measures ANOVA revealed a significant effect of "Session," $F(3,63)=$ $27.845, p<.001$, a significant effect of "Treatment," $F(2,21)=14.629, p<.001$, and "Session" × "Treatment," $F(6,63)=4.023, p=.002$, interaction. Post hoc tests showed that, once again, AMPH-treated rats spent less time on social interaction than did the SAL rats, $p<.001$. No such difference was seen between the PCP-treated and the SAL rats, $p=.618$. One-way ANOVA followed by LSD post hoc tests at each test 
Figure 2. Effects of acute amphetamine (AMPH; $1.5 \mathrm{mg} /$ $\mathrm{kg}, \mathrm{sc}$ ) or phencyclidine (PCP; $2.0 \mathrm{mg} / \mathrm{kg}, \mathrm{sc}$ ) administration versus saline $(\mathrm{SAL})$ treatment on social interaction in rats. Social interaction tests were conducted on 2 days for each rat, the first day of which used the same partner across the four 5-min sessions separated by a 10-min interval (AAAA), and the second of which used the same partner in the first three sessions, and an unfamiliar partner in the fourth session (AAAB). Data are expressed as mean \pm SEM total social behavior time summed from four sessions. ${ }^{*} p<.05$ versus SAL.

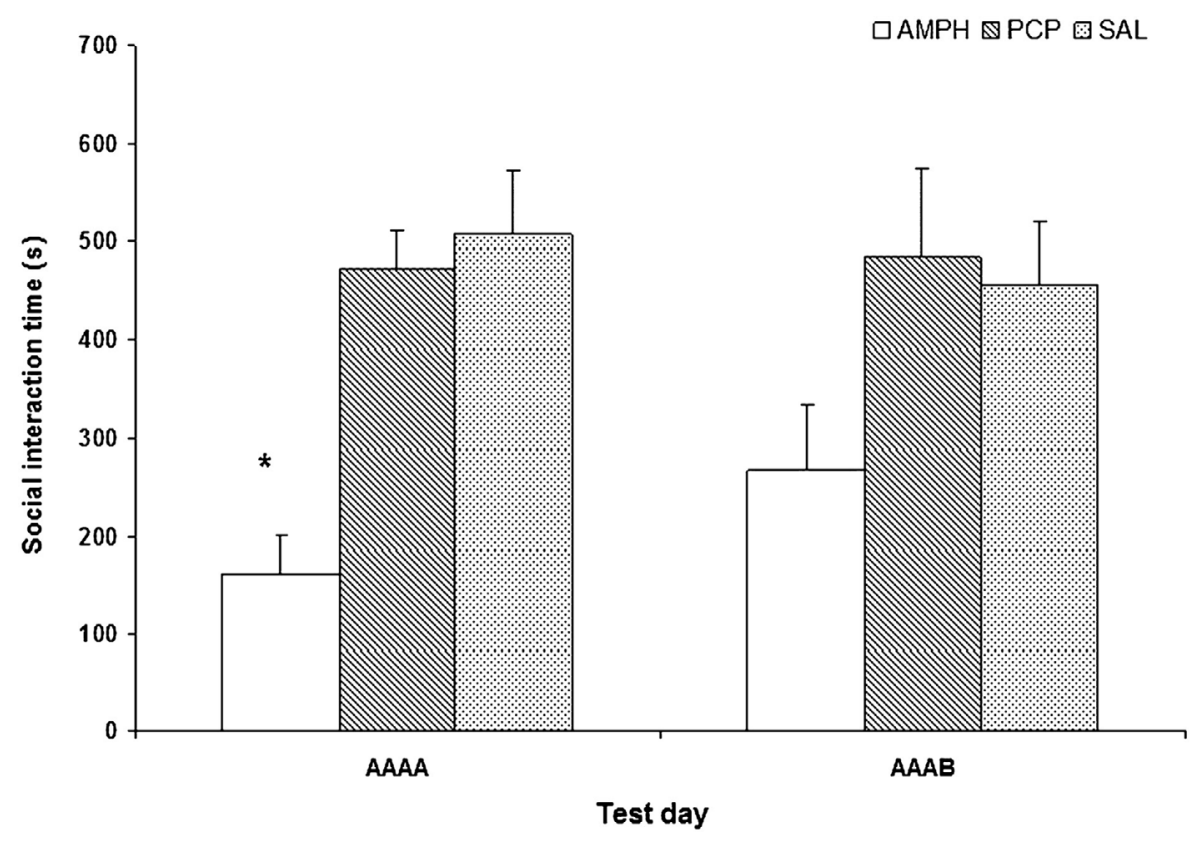

Figure 3. Effects of acute amphetamine (AMPH; $1.5 \mathrm{mg} / \mathrm{kg}, \mathrm{sc}$ ) or phencyclidine (PCP; $2.0 \mathrm{mg} / \mathrm{kg}, \mathrm{sC}$ ) administration versus saline (SAL) treatment on social interaction in rats across the four test sessions on the AAAA and AAAB days. Data are expressed as mean \pm SEM social interaction time recorded in each session. ${ }^{*} p<.05$ versus SAL.
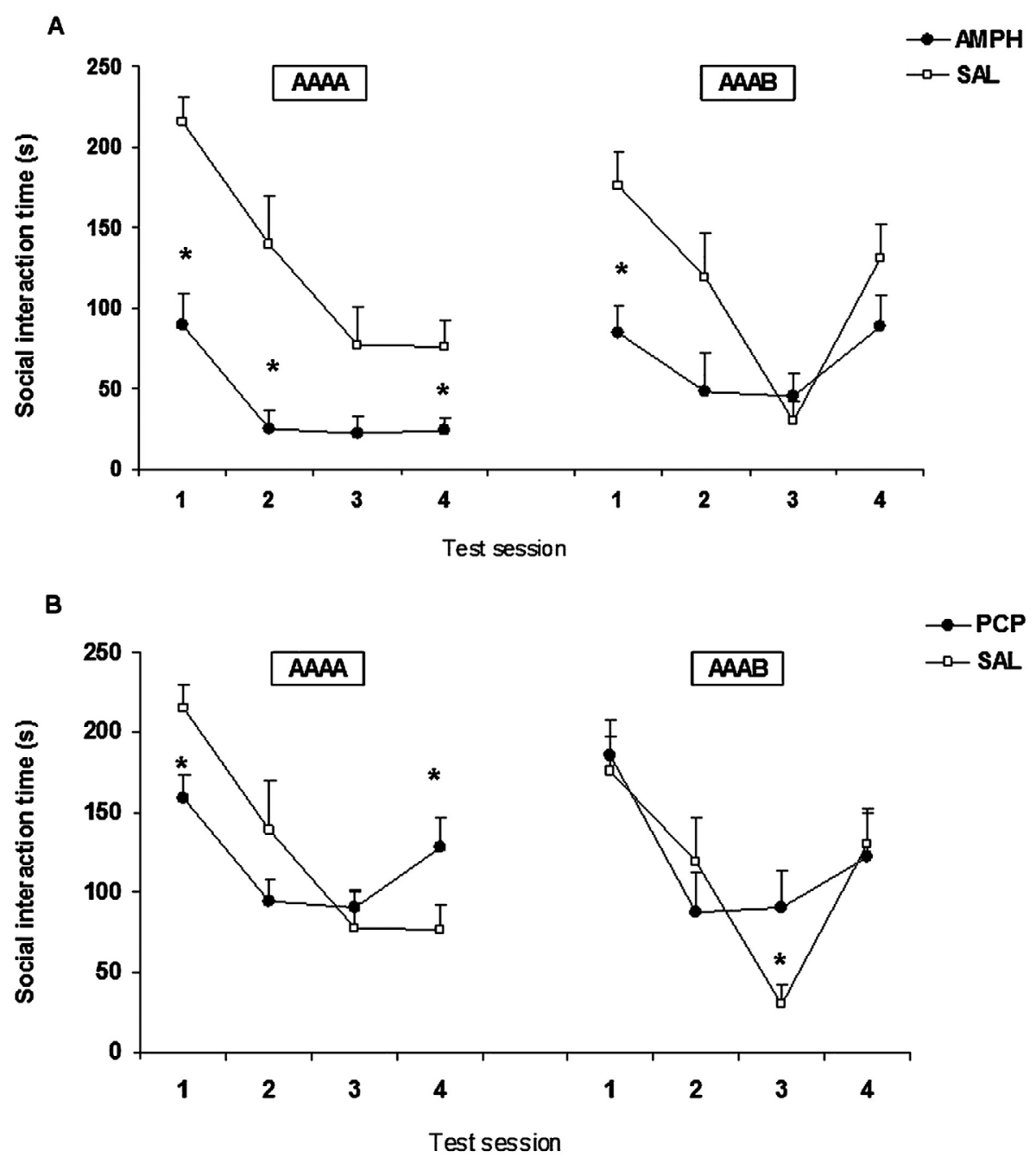


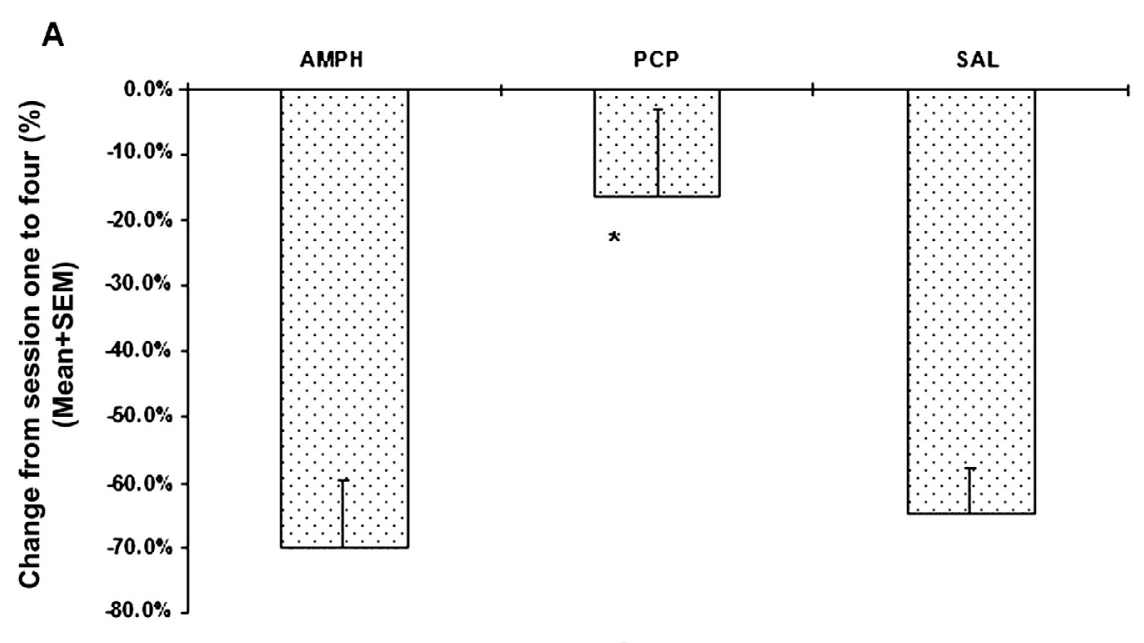

Figure 4. Effects of acute amphetamine (AMPH; $1.5 \mathrm{mg} / \mathrm{kg}, \mathrm{sc}$ ) or phencyclidine (PCP; $2.0 \mathrm{mg} / \mathrm{kg}, \mathrm{SC}$ ) administration versus saline (SAL) treatment on social recognition memory in rats measured on (A) day AAAA and (B) day AAAB. The social memory index was calculated as the percentage change in social interaction time from the first session to the fourth (for day AAAA) or the third session (for day $A A A B) .{ }^{*} p<.05$ versus SAL.

Group

B

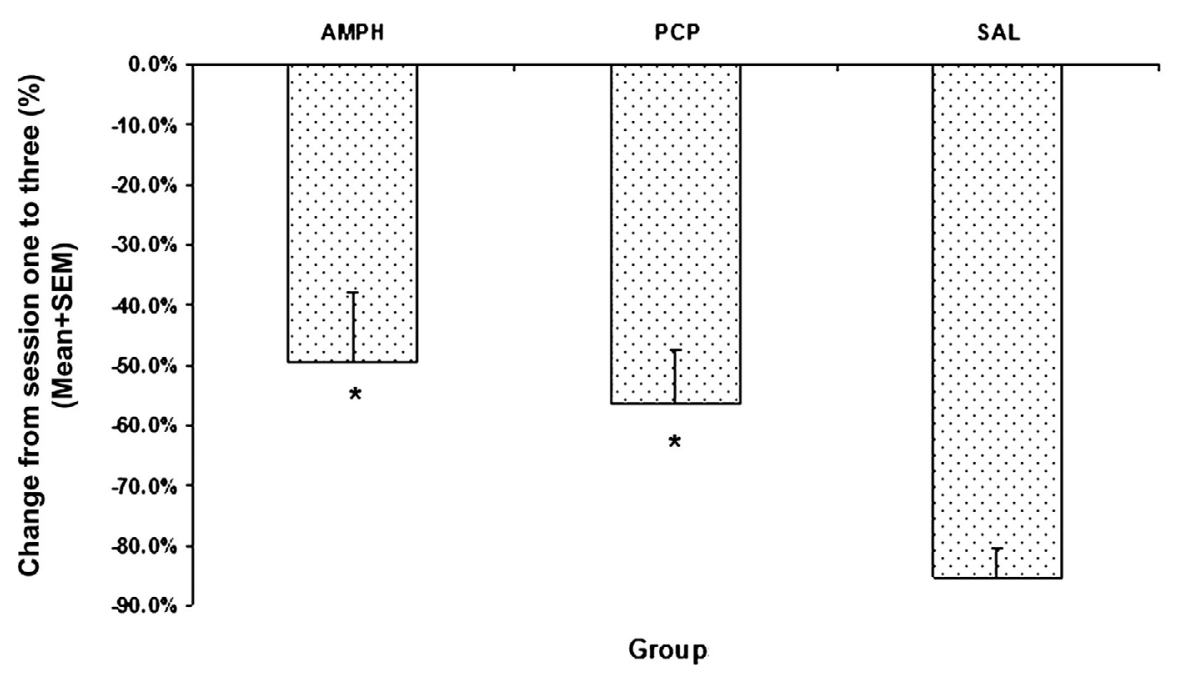

session showed that the AMPH-treated rats differed significantly from the SAL rats on the first, second, and fourth session, all $p<.028$ for each, whereas the PCPtreated rats differed from the SAL rats on the first session, $p=.019$, and the last session, $p=.026$. Inspection of Figure $3 \mathrm{~B}$ suggests that the PCP rats actually spent more time on social interaction on the last testing session. Overall, acute treatment of AMPH, but not PCP, produced a significant detrimental effect on social interaction.

For the AAAB day, repeated-measures ANOVA revealed a significant effect of "Session," $F(3,63)=$ $32.817, p<.001$, and "Session" $\times$ "Treatment" interaction, $F(6,63)=5.343, p<.001$, but no main effect of "Treatment," $F(2,21)=2.495, p=.107$. Post hoc tests showed that the AMPH-treated rats showed reduced social interaction only on the first session, $p=$ .004 versus SAL, whereas the PHP-treated rats showed increased social interaction on the third session, $p=$
.018 versus SAL. Once again, only the acute treatment of AMPH, but not PCP, disrupted social interaction.

\section{Acute PCP treatment disrupted social memory on both testing days, whereas acute AMPH only disrupted social memory on the second day of testing}

Using the social memory calculation formulas mentioned in the Methods section, we calculated the percentage change in social interaction time from the first session to the fourth or third session. The results are depicted in Figure 4. One-way ANOVA showed a significant main effect of "Treatment" for both the AAAA day, $F(2,23)=7.830, p=.003$, and the AAAB day, $F(2$, $23)=4.58 ; p=.022$. Post hoc tests revealed that the PCP-treated rats showed an impaired social memory on both days in comparison to the SAL rats, $p=.004$ and $p=.032$, respectively, whereas the AMPH-treated rats only showed an impaired social memory on the second 
Figure 5. Effects of withdrawal from amphetamine (AMPH) sensitization ( $3.0 \mathrm{mg} / \mathrm{kg}$, ip, daily for 7 days) versus saline $(\mathrm{SAL})$ treatment on social interaction and social memory in rats. Social interaction tests were conducted on two consecutive days (AAAA followed by AAAB). Data are expressed as mean \pm SEM social interaction time recorded in each session.

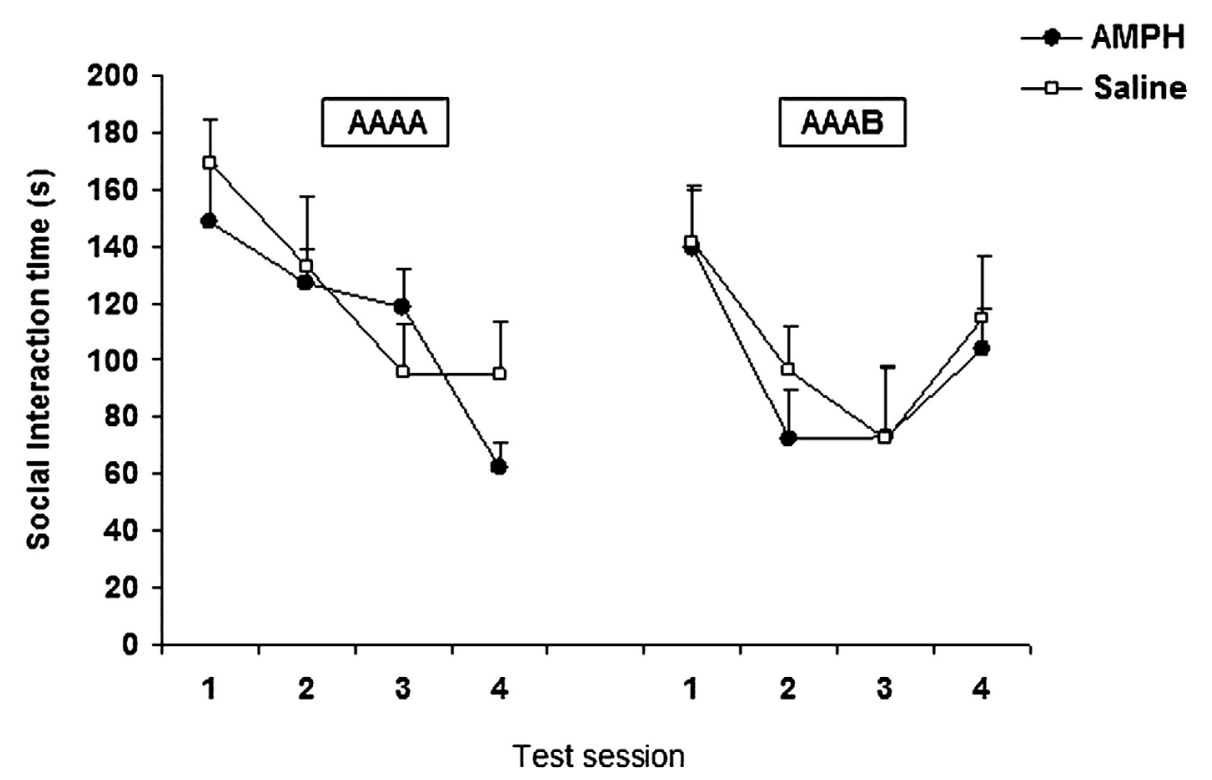

day of testing (i.e., AAAB day, $p=.009$ ), but not on the first day (i.e., AAAA day, $p=.733$ ).

Another measure of social recognition memory on the AAAB day was the recovery of social interaction from the third session to the fourth session due to the introduction of a novel partner. This effect was most conspicuous in the AMPH and SAL groups, and less so in the PCP group (Figure 3). Further analyses confirmed this observation. Repeated-measures ANOVAs examining the change from the third to the fourth session indicated a significant "Session" $\times$ "Treatment" interaction between the AMPH and SAL groups, $F(1$, $14)=5.839, p=.030$, and between the PCP and SAL groups, $F(1,14)=11.971, p=.004$, suggesting that both AMPH and PCP disrupted this measure of social memory, with PCP showing a more severe disruption than AMPH.

\section{Experiment 2: Effect of withdrawal from repeated AMPH treatment on social interaction and social recognition}

Figure 5 shows the social interaction (in seconds) of the rats that were previously treated with AMPH (3.0 $\mathrm{mg} / \mathrm{kg}$, ip) or saline for 7 days on each of the two test days. It appears that 1 -week withdrawal from repeated AMPH treatment did not affect social interaction or social memory. Both groups showed a progressive decline in the amount of time spent on social interaction across the four test sessions on the AAAA day, as reflected by a highly significant main effect of "Session," $F(3,42)=9.737, p<.001$. However, there was no significant main effect of "Treatment," $F(1,14)=0.397, p$ $=.539$, or "Treatment" $\times$ "Session" interaction, $F(3,42)$
$=1.201, p=.321$, suggesting that prior AMPH treatment did not significantly impact social interaction and social memory.

This lack of an effect of AMPH withdrawal on social interaction and social memory was also seen on the $\mathrm{AAAB}$ day. Both the AMPH and the SAL rats showed a progressive decline in the social interaction scores over the first three sessions and a rebound at the fourth session. There was a highly significant main effect of "Session," $F(3,42)=7.074, p=.001$, but no significant main effect of "Treatment," $F(1,14)=0.185, p=.673$, or "Treatment" $\times$ "Session" interaction, $F(3,42)=0.249$, $p=.861$. Inspection of Figure 5 shows that the introduction of a new partner at the fourth session reversed the declining trend in social interaction across the first three sessions in both groups equally.

\section{Experiment 3: Effect of withdrawal from repeated PCP treatment on social interaction and social recognition}

Figure 6A depicts the social interaction (in seconds) of the rats that were previously treated with PCP (5.0 $\mathrm{mg} / \mathrm{kg}$, twice daily, ip) or SAL for 7 days on each of the two test days. Similar to the data patterns seen in Experiment 2, 1-week withdrawal from repeated PCP treatment did not impair social interaction and social memory. Both the PCP and SAL groups decreased their social interaction progressively on the AAAA day. This observation was confirmed by statistical analyses showing a main effect of "Session," $F(3,42)=24.723$, $p<.001$, but no main effect of "Treatment," $F(1,14)=$ $0.051, p=.824$, or "Treatment" $\times$ "Session" interaction, $F(3,42)=0.161, p=.922$. 


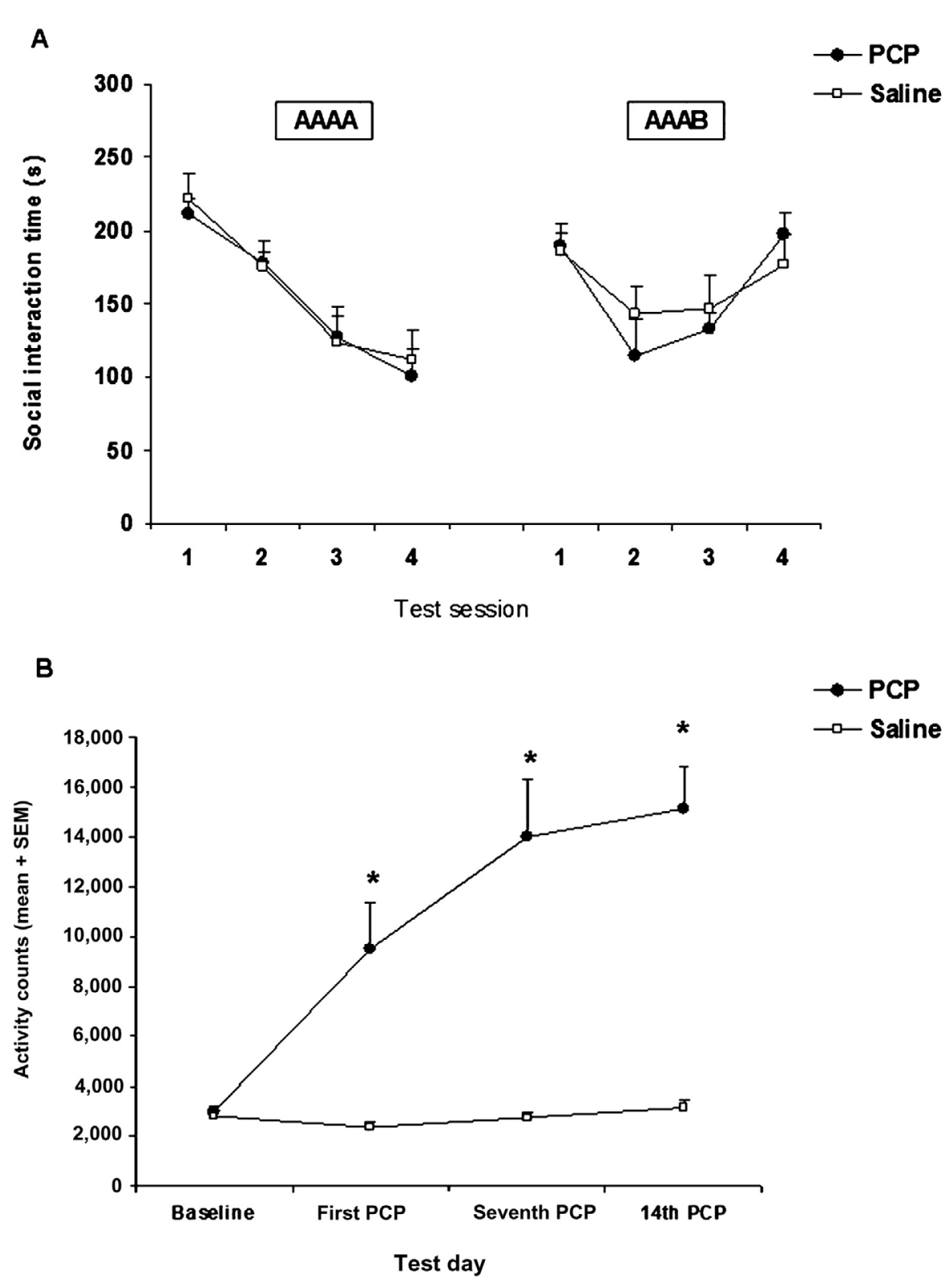

Figure 6. (A) Effects of withdrawal from phencyclidine (PCP) sensitization $(5 \mathrm{mg} /$ $\mathrm{kg}$, ip, twice daily for 7 days) versus saline (SAL) treatment on social interaction and social memory in rats. Social interaction data are expressed as mean \pm SEM time across the sessions. (B). PCP-induced hyperlocomotion (sensitization) during the induction phase on the day before the first drug injection, immediately after the first, seventh and 14th injection, are expressed as mean + SEM motor activity counts. ${ }^{*} p<.05$ versus SAL.

On the AAAB day, there was a clear initial decline and later rebound data pattern in the time spent on social interaction in both the PCP and SAL groups. Again, no PCP-withdrawal effect was detected, as reflected by a lack of significant effect of "Treatment," $F(1,14)=0.066$, $p=.801$, and "Treatment" $\times$ "Session" interaction, $F(3$, $42)=0.953, p=.424$. However, there was a significant main effect of "Session," $F(3,42)=8.207, p<.001$, suggesting that the introduction of a new partner at the fourth session completely reversed the social interaction decline in both groups. This further demonstrates that the rats were able to recognize their partners and to discriminate the old from the new.

In this experiment, we also measured motor activities during the induction phase of PCP sensitization.
As can be seen in Figure 6B, repeated PCP injections significantly enhanced motor activity throughout this period. There was a significant effect of treatment, $F(1$, $14)=114.964, p<.001$, a significant effect of tests, $F(3$, $42)=9.654, p<.001$, and treatment $\times$ tests interaction, $F(3,42)=8.957, p<.001$, suggesting that repeated PCP treatment at this dose did induce a behavioral sensitization effect.

\section{Discussion}

Impaired social interaction (e.g., social withdrawal) and social cognition are the core symptoms of schizophrenia and have been modeled extensively using rat 
social interaction paradigms (Green et al., 2004). In this study, we demonstrated that acute AMPH treatment caused a significant reduction in the amount of time spent on social interaction, but did not affect social recognition until the second drug test day. In contrast, acute PCP treatment had no effect on social interaction, but did significantly disrupt social recognition. Withdrawal from repeated AMPH or PCP treatment did not affect social interaction or social recognition, indicating a lack of long-term detrimental effect of repeated AMPH or PCP treatment. These results suggest that acute AMPH treatment may be useful in modeling social withdrawal-like behavior, whereas acute PCP treatment may be useful in modeling the social cognitive deficit of schizophrenia. Both withdrawal models (AMPH and PCP) based on the current treatment regimens are ineffective in providing a reliable model of social withdrawal and social cognitive deficits in schizophrenia.

In Experiment 1, we showed that a single injection of AMPH at $1.5 \mathrm{mg} / \mathrm{kg}$ was able to substantially reduce the time spent on social interaction. Because we only coded the interaction initiated by the AMPH-treated rats, this finding indicates that acute AMPH induced a social withdrawal-like behavior. This result is consistent with many reports in the literature showing that acute AMPH reduces social interaction in animals (Ellinwood, Sudilovsky, \& Nelson, 1973; Gambill \& Kornetsky, 1976; Schiorring \& Hecht, 1979; Steinpreis et al., 1994) and causes rats to actively withdraw from social contact (Kuppinger, Harrington, Kaczmerek, Panos, \& Steinpreis, 1996). However, this result does not agree with other studies showing that acute and continuous infusion of AMPH failed to reduce social activity in rats (Sams-Dodd, 1995, 1998a). This discrepancy is likely due to a variety of methodological differences between the studies, such as differences in rat strain (e.g., Wistar vs. Sprague-Dawley), AMPH dosage (e.g., $1.5 \mathrm{mg} / \mathrm{kg}$ vs. $0.125-4.0 \mathrm{mg} / \mathrm{kg}$ ), injection-testing interval (e.g., $45 \mathrm{~min}$ vs. $10 \mathrm{~min}$ ), testing duration (e.g., 5 min vs. $10 \mathrm{~min}$ or $30 \mathrm{~min}$ ), and testing conditions (e.g., low-light vs. regular light), etc. Thus, there may likely exist boundary conditions in which AMPH achieves its disruptive effect on social interaction, and figuring out these conditions in future studies may help us to understand how drug-environment interaction determines the behavioral effects of AMPH (Anagnostaras \& Robinson, 1996).

Although it is often reported that acute or subchronic treatment of PCP dose-dependently reduces social interaction, and this reduction is dissociable from the other effects of PCP, such as stereotypy, hyperlocomotion, and ataxia (Lee et al., 2005; Sams-Dodd, 1995, 1999), there are other reports in the literature that have failed to find such a disruptive effect, particularly at the dose used in the present study. For example, Steinpreis and her colleagues found that PCP at 1.0 $2.0 \mathrm{mg} / \mathrm{kg}$ was generally ineffective in disrupting rat social behavior, and a reliable disruptive effect started to appear when PCP reached $4.0 \mathrm{mg} / \mathrm{kg}$ (Steinpreis et al., 1994; Steinpreis \& Salamone, 1993). Recently, Mintz et al. (2005) used a more sophisticated behavioral analysis technique and examined the disruptive effect of PCP treatment on social interaction in an open fieldtest environment. They differentiated social interaction occurring in the home-base state and in the exploration state. Their results also showed that PCP at $2.0 \mathrm{mg} / \mathrm{kg}$ had no effect on total social interaction (measured as "social proximity," defined as the amount of time that rats are less than $20 \mathrm{~cm}$ apart), and no effect on social interaction in the home base during the first $10 \mathrm{~min}$ of testing. Similarly, Audet, Goulet, and Dore (2009) also failed to find any acute effect of PCP treatment on the total time spent in social interaction and the time spent on affiliative contacts (e.g., approach, sniffing, following). Thus, like AMPH, the socially disruptive effect of PCP is most likely dependent on the drug doses and testing conditions. The notion that only PCP, and not AMPH, can mimic social withdrawal should be abandoned in favor of the idea that both psychotomimetic drugs can induce social withdrawal under the appropriate conditions. Thus, efforts should be directed towards identifying the conditions in which AMPH and PCP disrupt or do not disrupt social behavior, and on what aspects of social behavior.

In group-living mammals such as rodents, the ability to recognize conspecifics (social memory) is critically important for reproduction, territorial defense, and the establishment of dominance hierarchies (Ferguson, Young, \& Insel, 2002). In the laboratory, social memory is often assessed reliably by measuring the reduction in investigation of a familiar partner relative to novel conspecifics (Thor \& Holloway, 1982). In the present study, we used two testing regimens (AAAA and $\mathrm{AAAB}$ ) and obtained two different measures of social memory: an across-session, progressive decline in the time spent on social interaction on the AAAA day, and a recovery of the interaction time in the last session on the AAAB day. Our results indicate that acute PCP treatment impaired social recognition, despite its lack of effect on social interaction per se. Acute AMPH treatment on the second test day 
(i.e., $\mathrm{AAAB}$ ) also showed a disruption of social recognition. To the best of our knowledge, this is the first report that shows the memory impairment effect of PCP (to a lesser extent, AMPH) in a natural social context, although PCP is known to disrupt learning and (working) memory in laboratory-based artificial tasks (Andersen \& Pouzet, 2004; Dunn \& Killcross, 2006; Jentsch \& Anzivino, 2004; Mandillo, Rinaldi, Oliverio, \& Mele, 2003). These findings are also consistent with a clinical observation showing that PCP psychosis normally occurs 20-40 min following single or repeated administration (Davies \& Beech, 1960), whereas AMPH psychosis usually occurs after a prolonged period of exposure (Bell, 1965; Ellinwood et al., 1973), confirming the clinical relevance of this preclinical approach.

The social memory disruptive effect of acute PCP is significant because it shows that an acute PCP treatment model may be a useful model of the social cognitive deficit of schizophrenia. In recent years, cognitive deficits associated with schizophrenia have received much attention (Green et al., 2004), of which social cognition is one (Floresco et al., 2005; Green et al., 2004). So far, much work has focused on attention, working memory, and executive functioning (Jentsch et al., 1997; Martinez, Oostwegel, Geyer, Ellison, \& Swerdlow, 2000; Schroeder, Schroeder, Darius, Grecksch, \& Sabel, 1998; Tenn, Fletcher, \& Kapur, 2003). There is still a glaring lack of naturalistic animal models of social cognitive deficits that cuts across mammalian species. The present study filled this critical gap by demonstrating that: (a) it is possible to develop an animal model based on PCP treatment to mimic the social cognitive deficit of schizophrenia; and (b) it is possible to examine other cognitive deficits, such as attention and working memory in a natural context. If future work confirms this effect of PCP, we could investigate the underlying neural and neurochemical mechanisms.

Repeated administration of AMPH and PCP induces behavioral and neurochemical changes that persist beyond the termination of drug treatment. In the present study, we failed to observe any long-term disruptive effect of AMPH and PCP withdrawal on rat social interaction or social cognition deficit. This lack of effect could not be attributed to the insensitivity of our social behavior testing procedure, because the rats were tested in a total of eight sessions in this paradigm and clearly adjusted the amount of time spent on social interaction when a novel partner was introduced after a familiar one. The lack of effect of AMPH withdrawal is consistent with what has been reported in the literature (Sams-Dodd, 1998a, 1998b). In contrast, the lack of effect of PCP withdrawal is inconsistent with others (Lee et al., 2005; Qiao et al., 2001; Sams-Dodd, 1995, 1999). However, a recent mice study using the same PCP treatment and withdrawal regimen as used in the present study also failed to detect a severe social impairment effect with repeated $\mathrm{PCP}$, and called for further analysis of the potential utility of subchronic PCP treatment for modeling the social withdrawal component of schizophrenia (Brigman, Ihne, Saksida, Bussey, \& Holmes, 2009). As in the case of AMPH studies, differences in testing schedules and PCP treatment regimens may contribute to the discrepancies among various PCP studies. As rightly pointed out by Fletcher et al. (2005), "the precise parameters of PCP treatment may be critically important in determining whether repeated treatment with PCP has long-term effects on cognition and on dopamine function" (p. 197).

The negative result from the PCP-treated rats on social recognition memory was unexpected, given that the same sensitization regimen (i.e., twice-daily injections of $5 \mathrm{mg} / \mathrm{kg}$ PCP for 7 days) has been shown to impair animal performance in a spatial working memory task, reduce basal dopamine utilization in the prefrontal cortex, and disrupt the animal's ability to flexibly adjust behavioral responses based on new or changed contingencies between stimulus and reward (Dunn \& Killcross, 2006; Jentsch et al., 1997; Jentsch \& Taylor, 2001; Rodefer et al., 2005). However, Stefani and Moghaddam (2002) also reported that rats treated with PCP or AMPH according to treatment regimens similar to ours did not show a lasting, significant working memory impairment in a discrete, paired-trials delayed alternation task. Egerton et al. (2008) also failed to observe any disruption of social behavior in rats repeatedly treated with PCP via injections or mini-pumps. Our study highlights a need to employ a diverse group of behavioral tasks to cross-validate animal models of the cognitive dysfunctions of schizophrenia. It is possible that PCP is less potent in disrupting cognitive function in an ethologically relevant behavioral context, such as a socially interactive paradigm, than in artificially created behavioral paradigms.

In conclusion, the present study demonstrated that social withdrawal is better induced by acute AMPH administration, and a social cognitive deficit is better induced by acute PCP administration. Withdrawals from repeated AMPH and PCP treatment are limited in the ability to induce social withdrawal and social cognitive deficits. Thus, in the development of animal models of schizophrenia, we suggest that acute AMPH treatment may be useful in modeling social withdrawal-like behavior, whereas acute PCP treatment may be useful 
in modeling the social memory deficit of schizophrenia. Both AMPH and PCP sensitization withdrawal models based on the regimens used in the present study and testing parameters are less likely to provide a reliable model of social withdrawal and social cognitive deficits in schizophrenia.

Acknowledgments - This study was funded in part by support from the Nebraska Tobacco Settlement Biomedical Research Development Funds, and a UNL Layman Award to Professor Ming Li. We thank the National Institute on Drug Abuse (NIDA) Chemical Synthesis and Drug Supply Program for providing the phencyclidine sample. We also thank Mrs. Alexa Mead for the help in running Experiment 3, and Ms. Rhiannon Sorenson and Ms. Ashley Rappana for help on coding rat social behavior.

\section{References}

Akers, K. G., Nakazawa, M., Romeo, R. D., Connor, J. A., McEwen, B. S., \& Tang, A. C. (2006). Early life modulators and predictors of adult synaptic plasticity. The European Journal of Neuroscience, 24(2), 547-554. doi: 10.1111/j.1460-9568.2006.04921.x

Anagnostaras, S. G., \& Robinson, T. E. (1996). Sensitization to the psychomotor stimulant effects of amphetamine: Modulation by associative learning. Behavioral Neuroscience, 110(6), 1397-1414.

doi: 10.1037/0735-7044.110.6.1397

Andersen, J. D., \& Pouzet, B. (2004). Spatial memory deficits induced by perinatal treatment of rats with PCP and reversal effect of d-serine. Neuropsychopharmacology, 29(6), 1080- 1090. doi: 10.1038/sj.npp.1300394

Arnt, J. (1995). Differential effects of classical and newer antipsychotics on the hypermotility induced by two dose levels of d-amphetamine. European Journal of Pharmacology, 283(1-3), 55-62.

Audet, M. C., Goulet, S., \& Dore, F. Y. (2009). Impaired social motivation and increased aggression in rats subchronically exposed to phencyclidine. Physiology and Behavior, 96(3), 394- 398. doi: 10.1016/j.physbeh.2008.11.002

Avena, N. M., \& Hoebel, B. G. (2003). Amphetamine-sensitized rats show sugar-induced hyperactivity (cross-sensitization) and sugar hyperphagia. Pharmacology, Biochemistry, and Behavior, 74(3), 635-639. doi: 10.1016/S0091-3057(02)01050-X

Bell, D. S. (1965). Comparison of amphetamine psychosis and schizophrenia. The British Journal of Psychiatry, 111, 701-707.

Brigman, J. L., Ihne, J., Saksida, L. M., Bussey, T. J., \& Holmes, A. (2009). Effects of subchronic phencyclidine $(\mathrm{PCP})$ treatment on social behaviors, and operant discrimination and reversal learning in C57BL/6J mice. Frontiers of Behavioral Neuroscience, 3, 2.

doi: 10.3389/neuro.08.002.2009

Davies, B. M., \& Beech, H. R. (1960). The effect of 1-arylcyclohexylamine (sernyl) on twelve normal volunteers. The Journal of Mental Science, 106, 912-924.

Dunn, M. J., \& Killcross, S. (2006). Clozapine but not haloperidol treatment reverses sub-chronic phencyclidineinduced disruption of conditional discrimination performance. Behavioural Brain Research, 175(2), 271-277. doi: 10.1016/j.bbr.2006.08.028

Egerton, A., Reid, L., McGregor, S., Cochran, S. M., Morris, B. J., \& Pratt, J. A. (2008). Subchronic and chronic PCP treatment produces temporally distinct deficits in attentional set shifting and prepulse inhibition in rats. $P s y$ chopharmacology, 198(1), 37-49. doi: 10.1007/s00213-008-1071-5

Ellenbroek, B. A., \& Cools, A. R. (1990). Animal models with construct validity for schizophrenia. Behavioural Pharmacology, 1(6), 469-490.

Ellenbroek, B. A., \& Cools, A. R. (2000). Animal models for the negative symptoms of schizophrenia. Behavioural Pharmacology, 11(3-4), 223-233.

Ellinwood, E. H., Jr., Sudilovsky, A., \& Nelson, L. M. (1973). Evolving behavior in the clinical and experimental amphetamine (model) psychosis. The American Journal of Psychiatry, 130(10), 1088-1093.

Ferguson, J. N., Young, L. J., \& Insel, T. R. (2002). The neuroendocrine basis of social recognition. Frontiers in Neuroendocrinology, 23(2), 200-224. doi: 10.1006/frne.2002.0229

Fletcher, P. J., Tenn, C. C., Rizos, Z., Lovic, V., \& Kapur, S. (2005). Sensitization to amphetamine, but not PCP, impairs attentional set shifting: Reversal by a D1 receptor agonist injected into the medial prefrontal cortex. Psychopharmacology, 183(2), 190- 200. doi: 10.1007/s00213-005-0157-6

Floresco, S. B., Geyer, M. A., Gold, L. H., \& Grace, A. A. (2005). Developing predictive animal models and establishing a preclinical trials network for assessing treatment effects on cognition in schizophrenia. Schizophrenia Bulletin, 31(4), 888-894. doi: 10.1093/schbul/sbi041

Gambill, J. D., \& Kornetsky, C. (1976). Effects of chronic damphetamine on social behavior of the rat: Implications for an animal model of paranoid schizophrenia. Psychopharmacology, 50(3), 215-223.

Gleason, S. D., \& Shannon, H. E. (1997). Blockade of phencyclidine-induced hyperlocomotion by olanzapine, clozapine and serotonin receptor subtype selective antagonists in mice. Psychopharmacology, 129(1), 79-84. doi: $10.1007 / \mathrm{s} 002130050165$

Green, M. F., Nuechterlein, K. H., Gold, J. M., Barch, D. M., Cohen, J., Essock, S., ... Marder, S. R. (2004). Approaching a consensus cognitive battery for clinical 
trials in schizophrenia: The NIMH-MATRICS conference to select cognitive domains and test criteria. Biological Psychiatry, 56(5), 301-307. doi: 10.1016/j.biopsych.2004.06.023.

Guy, A. P., \& Gardner, C. R. (1985). Pharmacological characterisation of a modified social interaction model of anxiety in the rat. Neuropsychobiology, 13(4), 194-200.

Holloway, W. R., Jr., \& Thor, D. H. (1988). Social memory deficits in adult male rats exposed to cadmium in infancy. Neurotoxicology and Teratology, 10(3), 193-197. doi: 10.1016/0892-0362(88)90017-7

Jentsch, J. D., \& Anzivino, L. A. (2004). A low dose of the alpha2 agonist clonidine ameliorates the visual attention and spatial working memory deficits produced by phencyclidine administration to rats. Psychopharmacology, 175(1), 76-83. doi: 10.1007/s00213-004-1772-3

Jentsch, J. D., \& Taylor, J. R. (2001). Impaired inhibition of conditioned responses produced by subchronic administration of phencyclidine to rats. Neuropsychopharmacology, 24(1), 66-74. doi: 10.1038/sj.npp.1395582

Jentsch, J. D., Tran, A., Le, D., Youngren, K. D., \& Roth, R. H. (1997). Subchronic phencyclidine administration reduces mesoprefrontal dopamine utilization and impairs prefrontal cortical-dependent cognition in the rat. Neuropsychopharmacology, 17(2), 92-99.

Kilts, C.D. (2001). The changing roles and targets for animal models of schizophrenia. Biological Psychiatry, 50(11), 845-855.

Krishnan, R. R., Keefe, R., \& Kraus, M. (2009). Schizophrenia is a disorder of higher order hierarchical processing. Medical Hypotheses, 72(6), 740-744.

doi: 10.1016/j.mehy.2008.12.039

Kuppinger, H., Harrington, A. H., Kaczmerek, H. J., Panos, J. J., \& Steinpreis, R. E. (1996). The effects of phencyclidine and amphetamine on social behavior in tether-restrained and freely moving rats. Experimental and Clinical Psychopharmacology, 4(1), 77-81.

Lee, P. R., Brady, D. L., Shapiro, R. A., Dorsa, D. M., \& Koenig, J. I. (2005). Social interaction deficits caused by chronic phencyclidine administration are reversed by oxytocin. Neuropsychopharmacology, 30(10), 1883-1894. doi: 10.1038/sj.npp.1300722

Mandillo, S., Rinaldi, A., Oliverio, A., \& Mele, A. (2003). Repeated administration of phencyclidine, amphetamine and MK-801 selectively impairs spatial learning in mice: A possible model of psychotomimetic druginduced cognitive deficits. Behavioural Pharmacology, 14(7), 533-544.

Martinez, Z. A., Oostwegel, J., Geyer, M. A., Ellison, G. D., \& Swerdlow, N. R. (2000). "Early" and "late" effects of sustained haloperidol on apomorphine- and phencyclidine-induced sensorimotor gating deficits. Neuropsychopharmacology, 23(5), 517-527.

doi: 10.1038/sj.npp.1395555
Mintz, M., Russig, H., Lacroix, L., \& Feldon, J. (2005). Sharing of the home base: A social test in rats. Behavioural Pharmacology, 16(4), 227-236.

Natesan, S., Reckless, G. E., Nobrega, J. N., Fletcher, P. J., $\&$ Kapur, S. (2006). Dissociation between in vivo occupancy and functional antagonism of dopamine D2 receptors: Comparing aripiprazole to other antipsychotics in animal models. Neuropsychopharmacology, 31(9), 18541863. doi: 10.1038/sj.npp.1300983

Prediger, R. D., Batista, L. C., Miyoshi, E., \& Takahashi, R. N. (2004). Facilitation of short-term social memory by ethanol in rats is mediated by dopaminergic receptors. Behavioural Brain Research, 153(1), 149-157. doi: 10.1016/j.bbr.2003.11.009

Qiao, H., Noda, Y., Kamei, H., Nagai, T., Furukawa, H., Miura, H., ... Nabeshima, T. (2001). Clozapine, but not haloperidol, reverses social behavior deficit in mice during withdrawal from chronic phencyclidine treatment. Neuroreport, 12(1), 11-15.

Reske, M., Habel, U., Kellermann, T., Backes, V., Jon Shah, N., von Wilmsdorff, M., ... Schneider, F. (2009). Differential brain activation during facial emotion discrimination in first-episode schizophrenia. Journal of Psychiatric Research, 43(6), 592-599.

doi: 10.1016/j.jpsychires.2008.10.012

Rodefer, J. S., Murphy, E. R., \& Baxter, M. G. (2005). PDE10A inhibition reverses subchronic PCP-induced deficits in attentional set-shifting in rats. The European Journal of Neuroscience, 21(4), 1070-1076. doi: 10.1111/j.1460-9568.2005.03937.x

Sams-Dodd, F. (1995). Distinct effects of d-amphetamine and phencyclidine on the social behaviour of rats. Behavioural Pharmacology, 6(1), 55-65.

Sams-Dodd, F. (1998a). Effects of continuous d-amphetamine and phencyclidine administration on social behaviour, stereotyped behaviour, and locomotor activity in rats. Neuropsychopharmacology, 19(1), 18-25. doi: 10.1038/sj.npp.1395181

Sams-Dodd, F. (1998b). A test of the predictive validity of animal models of schizophrenia based on phencyclidine and d-amphetamine. Neuropsychopharmacology, 18(4), 293-304. doi: 10.1038/sj.npp.1395142

Sams-Dodd, F. (1999). Phencyclidine in the social interaction test: An animal model of schizophrenia with face and predictive validity. Reviews in the Neurosciences, 10(1), 59-90.

Schiorring, E., \& Hecht, A. (1979). Behavioral effects of low, acute doses of $\mathrm{d}$-amphetamine on the dyadic interaction between mother and infant vervet monkeys (Cercopithecus aethiops) during the first six postnatal months. Psychopharmacology, 64(2), 219-224.

Schroeder, U., Schroeder, H., Darius, J., Grecksch, G., \& Sabel, B. A. (1998). Simulation of psychosis by continuous delivery of phencyclidine from controlled-release 
polymer implants. Behavioural Brain Research, 97(12), 59-68.

Sills, T. L., Greenshaw, A. J., Baker, G. B., \& Fletcher, P. J. (2000). Subchronic fluoxetine treatment induces a transient potentiation of amphetamine-induced hyperlocomotion: Possible pharmacokinetic interaction. Behavioural Pharmacology, 11(2), 109- 116.

Srisurapanont, M., Ali, R., Marsden, J., Sunga, A., Wada, K., \& Monteiro, M. (2003). Psychotic symptoms in methamphetamine psychotic in-patients. The International Journal of Neuropsychopharmacology, 6(4), 347-352. doi: 10.1017/S1461145703003675

Stefani, M. R., \& Moghaddam, B. (2002). Effects of repeated treatment with amphetamine or phencyclidine on working memory in the rat. Behavioural Brain Research, 134(1-2), 267-274. doi: 10.1016/S0166-4328(02)00040-2

Steinpreis, R. E., \& Salamone, J. D. (1993). The role of nucleus accumbens dopamine in the neurochemical and behavioral effects of phencyclidine: A microdialysis and behavioral study. Brain Research, 612(1-2), 263-270. doi: 10.1016/0006- 8993(93)91671-E.

Steinpreis, R. E., Sokolowski, J. D., Papanikolaou, A., \& Salamone, J. D. (1994). The effects of haloperidol and clozapine on PCP- and amphetamine-induced suppression of social behavior in the rat. Pharmacology, Biochemistry, and Behavior, 47(3), 579-585. doi: 10.1016/0091-3057(94)90162-7

Sun, T., Hu, G., \& Li, M. (2009). Repeated antipsychotic treatment progressively potentiates inhibition on phencyclidine-induced hyperlocomotion, but attenuates inhibition on amphetamine-induced hyperlocomotion:
Relevance to animal models of antipsychotic drugs. European Journal of Pharmacology, 602(2-3), 334-342. doi: 10.1016/j.ejphar.2008.11.036

Tanaka, K., Suzuki, M., Sumiyoshi, T., Murata, M., Tsunoda, M., \& Kurachi, M. (2003). Subchronic phencyclidine administration alters central vasopressin receptor binding and social interaction in the rat. Brain Research, 992(2), 239-245. doi: 10.1016/j.brainres.2003.08.050.

Tenn, C. C., Fletcher, P. J., \& Kapur, S. (2003). Amphetamine-sensitized animals show a sensorimotor gating and neurochemical abnormality similar to that of schizophrenia. Schizophrenia Research, 64(2-3), 103114. doi: 10.1016/S0920-9964(03)00009-4

Tenn, C. C., Kapur, S., \& Fletcher, P. J. (2005). Sensitization to amphetamine, but not phencyclidine, disrupts prepulse inhibition and latent inhibition. Psychopharmacology, 180(2), 366- 376. doi: $10.1007 / \mathrm{s} 00213-005-2253-\mathrm{z}$

Thor, D. H., \& Holloway, W. R. (1982). Social memory of the male laboratory rat. Journal of Comparative and Physiological Psychology, 96(6), 1000-1006.

Wyvell, C. L., \& Berridge, K. C. (2001). Incentive sensitization by previous amphetamine exposure: Increased cuetriggered "wanting" for sucrose reward. Journal of Neuroscience, 21(19), 7831-7840.

Young, K. A., Gobrogge, K. L., \& Wang, Z. (2011). The role of mesocorticolimbic dopamine in regulating interactions between drugs of abuse and social behavior. Neuroscience and Biobehavioral Reviews, 35(3), 498-515. doi: 10.1016/j.neubiorev.2010.06.004 